\title{
A Comprehensive Review on Process and Technological Aspects of Wood- Plastic Composites
}

\author{
Sumit Manohar Yadav ${ }^{1, *}$, Muhammad Adly Rahandi Lubis ${ }^{2}$, Kapil Sihag ${ }^{1}$ \\ ${ }^{1}$ Department of Forest Products and Utilization, Forest College and Research Institute Hyderabad. Mulugu, Siddipet Rd., \\ Hyderabad, Telangana, 500014, India \\ ${ }^{2}$ Research Center for Biomaterials, Indonesian Institute of Sciences (LIPI). Jl. Raya Bogor Km. 46 Cibinong, Bogor, 16911, West \\ Java, Indonesia \\ * Corresponding author. E-mail address: sumitmyadav13@gmail.com
}

ARTICLE HISTORY:

Received: 12 April 2021

Peer review completed: 20 May 2021

Received in revised form: 28 May 2021

Accepted: 30 May 202

KEYWORDS:

Additive manufacturing Adhesion

Fabrication techniques

Mechanical and physical propertie Wood-plastic composites

(C) 2021 The Author(s). Published by Department of Forestry, Faculty of Agriculture, University of Lampung in collaboration with Indonesia Network for Agroforestry Education (INAFE).

This is an open access article under the CC BY-NC license:

https://creativecommons.org/licenses/by$\mathrm{nc} / 4.0 \%$

\begin{abstract}
This review deals with recent works on the process and technological aspects of wood-plastic composites (WPCs) manufacturing. WPCs relate to any composites that are built from wood and non-wood fibers and thermoplastic polymers. Recent progress relevant to wood-plastic composites has been reviewed in this article. The process and technological aspects of WPC, such as raw materials, fabrication, mechanical, physical, thermal, and morphological properties, were outlined comprehensively. The manufacturing process of WPCs is an important aspect of WPCs production. Manufacturing methods like compression molding and pultrusion have some limitations. Extrusion and injection molding processes are the most widely used in WPCs due to their effectiveness. Recent developments dealing with WPCs and the use of different kinds of nanofillers in WPCs have also been presented and discussed. Nanoclays are widely used as nanofillers in WPCs because they represent an ecofriendly, readily available in large quantity, and inexpensive filler. WPCs can be found in a wide range of applications from construction to the automotive industry.
\end{abstract}

\section{Introduction}

Wood-plastic composites (WPCs) refer to composites that are composed of wood and nonwood fibers and thermoset and thermoplastic polymers. Thermosets polymers used in WPCs are classified as polymers that cannot be melted by heating. Epoxies and phenolic resins are examples of these polymers. Thermoplastic polymers are plastics that can be repeatedly melted, which allow wood fibers to be mixed with the plastic to form WPC products. Common thermoplastics for WPCs manufacture are polypropylene (PP), polyethylene (PE), and polyvinyl chloride (PVC) (Panthapulakkal et al. 2006).

WPCs were found in Italy in the 1970s and popularized in North America in the early 1990s. WPCs spread to India, Singapore, Malaysia, Japan, and China in the early 21st century (Ashori 2008). The best properties of WPCs can be obtained by combining the neat components and thereby exhibit outstanding performance. An example is wood flour, which is a readily available and inexpensive WPCs material that can lower resin costs, improve stiffness, and environmentally friendly. High dimensional stability, low water uptake, and high durability against fungi and 
insects compared with wood during their lifetime are the main advantages of WPCs (Arao et al. 2014). Therefore, WPCs are widely used in exterior applications, such as decking for terraces and balconies.

The WPCs manufacturing process usually consists of two steps, i.e., the compounding and the forming. Briefly, the compounding process of wood and other additives is performed to produce a homogeneous composite material by incorporating into a molten thermoplastic. The composite material is then formed into a product, and profile extrusion, injection molding, and compression molding are used as the common forming process (Clemons 2002).

Owing to their favorable properties like low density, low cost, renewability, recyclability, and desirable mechanical properties, WPCs are gaining interest in both academic and industrial sectors (Ashori 2008). The better dimensional stability and favorable mechanical properties made WPCs one of the preferred building materials (El-Haggar and Kamel 2011). Nevertheless, wood flour and thermoplastics have different natures, therefore imposing severe incompatibility during the manufacturing process, and eventually leads to lower interfacial adhesion between thermoplastics and wood flour (Lei et al. 2015).

Fillers can be used in order to enhance the physical and mechanical properties of WPC. The wood flour can be modified by acetylation, grafting silane, heating, and sodium hydroxide treatment to improve the physical and mechanical properties. In addition, the incorporation of nanoparticles such as nanoclay and carbon nanotubes (CNTs) during WPCs manufacturing is known for improving the overall properties of WPCs due to their high surface area, low density, and high Young modulus. Those nanomaterials have shown promising results, such as high tensile and flexural strength, high modulus, less water absorption and good thermal stability (Faruk and Matuana 2008).

\section{Components of Wood-Plastic Composites}

\subsection{Wood Fibers}

Wood fibers usually contain cellulose, hemicellulose, pectin, lignin, water-soluble ingredients, and wax (Hong et al. 2020; John and Thomas 2008). The actual composition of these materials in wood fibers, though, varies from species to species. Here, water-soluble constituents and wax are considered as extractives since cellulose, hemicellulose, and lignin are considered to be the basic components with regard to physical properties (John and Thomas 2008). Generally, more than $50 \%$ of wood fibers are cellulose. Wood fibers are considered as hollow cellulose fibrils that are bonded together by a lignin and hemicellulose complex matrix (Jayaraman 2003). Table 1 presents the chemical compositions of some natural fibers.

The moduli of cellulose-based materials are very different from each other. For instance, solid wood has Young's modulus of around $10 \mathrm{GPa}$. The modulus of a single pulp fiber can be as high as $40 \mathrm{Gpa}$ after pulping process. Microfibrils can be separated from pulp fibers after mechanical disintegration and hydrolysis. The modulus of microfibrils is around $70 \mathrm{GPa}$. Finally, the modulus of cellulose nanocrystals is obtained by theoretical calculation, and this could be as high as $250 \mathrm{GPa}$ (Gassan and Bledzki 2000). From the same literature, the moduli values of wood fibers range from 10 to $90 \mathrm{GPa}$ (Gassan and Bledzki 2000). From these numbers, we can say that it is reasonable to compound WF with plastics to increase the modulus of resins of interest because the modulus of wood fibers ( $40 \mathrm{GPa})$ is much higher than that of most plastics. The high moduli of wood fibers make these good candidates as plastic reinforcements. 
Table 1. Selected chemical composition of some natural fibers (Kabir et al. 2012)

\begin{tabular}{lccccc}
\hline Fibers & $\begin{array}{c}\text { Cellulose } \\
(\mathbf{w t} \%)\end{array}$ & $\begin{array}{c}\text { Lignin } \\
\mathbf{( w t \% )}\end{array}$ & $\begin{array}{c}\text { Hemicellulose } \\
\mathbf{( w t \% )}\end{array}$ & $\begin{array}{c}\text { Pectin } \\
\mathbf{( w t \% )}\end{array}$ & $\begin{array}{c}\text { Wax } \\
\mathbf{( w t \% )}\end{array}$ \\
\hline Cotton & 82.7 & $0.7-1.6$ & 5.7 & - & 0.6 \\
Flax & 71 & 2.2 & $18.6-20.6$ & 2.3 & 1.7 \\
Jute & $61-71.5$ & $12-13$ & $13.6-20.6$ & 2.3 & 1.7 \\
Hemp & $70.2-74.4$ & $3.7-5.7$ & $17.9-22.4$ & 0.9 & 0.8 \\
Ramie & $68.6-76.2$ & $0.6-0.7$ & $13.1-16.7$ & 1.9 & 0.3 \\
Sisal & $67-78$ & $8-11$ & $10-14.2$ & 10 & 2 \\
Palf & $70-82$ & $5-12$ & - & - & - \\
\hline
\end{tabular}

Economical production, low specific weight, higher specific strength, and stiffness are factors that growing interest in wood fibers (Kim et al. 2006). Solid wood also has relatively safer handling and working conditions than synthetic materials (John and Thomas 2008). In addition, wood fibers are non-abrasive to molding and mixing equipment, reducing the cost of production. The most important aspect of wood fibers is environmentally friendly. Wood fibers are a kind of renewable material with low production energy, and they do not return excess carbon dioxide into the atmosphere when composted or combusted. The processing of wood fibers is friendly with better working conditions, and therefore there will be reduced health risks such as respiratory irritation. Wood fibers possess high electrical resistance, thermal recycling, good acoustic insulating properties, and worldwide availability (John and Thomas 2008). Data on the annual production of natural fibers is mentioned in Table 2.

Table 2. Annual production of natural fibers (Antov et al. 2017)

\begin{tabular}{lc}
\hline \multicolumn{1}{c}{ Natural fiber } & Annual production (metric tones) \\
\hline Wood (hardwoods and softwoods) & $1,750,000,000$ \\
Softwood kraft pulp & $26,000,000$ \\
Sisal & 378,000 \\
Kenaf & 970,000 \\
Hemp & 214,000 \\
Bamboo & $30,000,000$ \\
Wheat & $720,000,000$ \\
Jute & $2,300,000$ \\
\hline
\end{tabular}

Nevertheless, certain drawbacks, such as low thermal stability, the tendency to form aggregates during processing, seasonal quality variations, and low water resistance, greatly reduce the potential of wood fibers to be used as reinforcement for WPCs (Kim et al. 2006). The high water absorption of wood fibers leads to swelling, which leads to low mechanical properties and decreases the dimensional instability of WPCs. One of the major drawbacks of wood fibers is the poor compatibility between the fibers and thermoset/thermoplastic polymers, which results in nonhomogeneous dispersion of fibers within the matrix. Most polymers, especially thermoplastics, are nonpolar (hydrophobic) substances, which are not compatible with polar (hydrophilic), such as wood fibers and, therefore, can result in poor adhesion between polymer and fiber in WPC (Ashori 2008). 
The processing temperature is another problem that restricts the option for the matrix material in WPCs. Wood fibers are composed of cellulose, hemicellulose, and lignin, and therefore their thermal treatment leads to a variety of physical and chemical alterations. Thermal decomposition of wood fibers leads to low organoleptic properties and deterioration of their mechanical properties. Thermal degradation also results in the generation of gaseous products when using temperatures above $200^{\circ} \mathrm{C}$, which can create low density, high porosity, and low mechanical properties (Georgopoulos et al. 2005). Wood fibers used in WPCs have a large variety of sizes, shapes, and characteristics, which determined the properties of the final product. The surface chemistry and fiber aspect ratio, in particular, are also important characteristics that determined the properties of WPCs. Aspect ratio means average length over the diameter of wood fibers, which change from species to species. For example, hardwood fibers derived from aspen or birch are more rigid compared to softwood fibers (spruce), which made hardwood not a good option as a material for WPCs (Ashori 2008).

Other factors such as the size of fibers, chemical compositions, thickness, density, fiber percentage, morphological structure, and amount and type of bonding agent are also important for the mechanical properties of WPCs. The pulping process of wood determined the mechanical properties of wood fibers even within the same species (Ren et al. 2014). There are two main options of wood materials, i.e., wood flour and wood fibers. Wood flour and wood fibers are the by-products or waste products of wood material. In fact, wood flour is much more widely available than wood fibers. Besides, it is reportedly cheaper, free-flowing, and much easier to process than wood fibers (Sihombing et al. 2012). The wood flour is available in many sizes, from 20 mesh (coarse) to 400 mesh (extra fine). For WPCs manufacturing, a satisfactory result composition based on criteria between price, performance, and ease of processing was the wood flour with a size of 40 mesh (Table 3).

Table 3. Effect of wood flour particle size on the performance of WPCs made of wood and polypropylene (Sihombing et al. 2012)

\begin{tabular}{cccc}
\hline Mesh Size & $\begin{array}{c}\text { Notched Izod Impact } \\
(\mathbf{J} / \mathbf{M})\end{array}$ & $\begin{array}{c}\text { Tensile Strength } \\
(\mathbf{M P a})\end{array}$ & $\begin{array}{c}\text { Bending Stiffness } \\
(\mathbf{G P a})\end{array}$ \\
\hline $20(841$ microns $)$ & 27 & 23.3 & 2.98 \\
$40(400$ microns $)$ & 21 & 24.4 & 3.10 \\
$80(177$ microns $)$ & 19 & 24.8 & 3.12 \\
$120(125$ microns $)$ & 17 & 24.2 & 2.84 \\
\hline
\end{tabular}

\subsection{Plastics used to Formulate Wood-Plastic Composites}

Because wood flour (WF) will be burnt when the processing temperature is above $200^{\circ} \mathrm{C}$, the use of plastic as the matrix in WPCs is limited. Polyethylene (PE), polyvinyl chloride (PVC), and polypropylene (PP) are the most common matrix materials in WPCs. This is because the price of these plastics is lower than that of other engineering plastics, and their processing temperature is lower than $200^{\circ} \mathrm{C}$.

\subsubsection{Polyethylene (PE)}

$\mathrm{PE}$ is a kind of thermoplastic polymer melting at about $80-130^{\circ} \mathrm{C}$ with density of $0.91-0.96$ $\mathrm{g} / \mathrm{cm}^{3}$. It is commercially produced from the polymerization of ethylene. PE is classified into low 
density polyethylene (LDPE), medium density polyethylene (MDPE), and high density polyethylene (HDPE) (Homami et al. 2013).

The photo stabilizer could influence the properties of HDPE/WF composites Taib et al. (2010). The study revealed that the addition of ultraviolet stabilizer (UVA) could limit and minimized the adverse effect of natural weathering on HDPE/WF WPCs. In their research, Al Maadeed et al. (2013) used LDPE, MDPE, and HDPE to examine the influence of chain structure on the dispersion and adhesion in wood fiber reinforced polymer composites. The long chain branching (LCB) in LDPE resulted in higher increases both in storage modulus in the melt and elastic modulus in the solid state. They also found that the crystal domain of HDPE could increase the tensile strength and less fiber pull out upon the addition of glass fibers.

The influence of moisture on the sorption characteristics of LDPE-based WPCs incorporated with pineapple-leaf fibers (PALF/LDPE) has been studied by George et al. (1995) by immersion of PALF/LDPE composite in distilled water at 28,50 , and $70^{\circ} \mathrm{C}$. It was found that the fiber/polymer matrix bonding was getting weaker with increasing moisture content, resulting in interfacial failure and decreased mechanical properties.

The use of saline as a crosslinker in WF (pine wood flour) and HDPE has been studied by Bengtsson et al. (2005). A hot water test followed by tensile testing showed that the crosslinked WPCs were less susceptible to water absorption (WA) than non-crosslinked WPCs. Moreover, the crosslinked WPCs did not significantly decrease tensile strength compared to the non-crosslinked WPCs. Scanning electron microscopy (SEM) displayed better compatibility and adhesion between the HDPE and WF for crosslinked WPCs.

\subsubsection{Polyvinyl chloride (PVC)}

PVC is another common plastic used in WPCs. Unlike HDPE and PP, the molecular structure of PVC is such that it is hydrophilic. Therefore, PVC is more compatible with WF. In addition, PVC contains chlorine which acts as a flame retardant in plastics. Because of this, the flammability of PVC-based WPCs will be less compared with HDPE or PP-based WPCs. However, PVC is often referred to as the "Poison plastic", and this is due to the toxin (dioxins) that can release when exposed to fire during manufacturing (Yeh 2007). The materials which contain toxins can be harmful to the market of PVC-based WPCs.

The thermal decomposition, mechanical properties, and fire retardancy of PVC-WF/zinc borate (ZB) composites were investigated by Fang et al. (2013). The authors stated that WF exhibited better flame retardancy but had little effect on smoke suppression. The incorporation of ZB did not significantly increase the flame retardancy of the WF-PVC composite, and some negative effects on the strength properties of WPCs were observed. In another research, Bishay et al. (2011) studied PVC-based WPCs' mechanical and thermal properties loaded with different concentrations of aluminium powder. It was found that mechanical strength values decrease with increasing the aluminium powder content. They also observed that the thermal stability of composite samples increases with increasing aluminium content.

\subsubsection{Polypropylene (PP)}

PP occupies a prominent role in the WPC market. The advantage of PP is that it possesses slightly higher stiffness than HDPE (Yeh and Gupta 2008). PP-based WPCs simply offer another choice for WPCs. Arao et al. (2014) used fire retardants to improve the fire performance of PP/ 
WF (pine wood flour) composites. The study revealed that the tensile strength and modulus of the composites decreased with the loading of retardants. Bhaskar et al. (2012) evaluated the properties of PP/WF (pine wood flour) wood-plastic composites. They concluded that the incorporation of maleic anhydride grafted polypropylene (MAPP) coupling agent in composite formulation improved the interfacial bonding between matrix and wood flour and the stability of WPC. Fabiyi et al. (2008) investigated the effects of outside and accelerated weathering on the chemical change, and the visual appearance of WPC formulations based on HDPE and PP were investigated. The researchers believe that the HDPE-based WPC decreased lightness, carbonyl concentrations, and wood content loss compared to PP-based WPC.

Effect of bark flour content on mechanical properties of WPC based on PP/WF and bark flour from Abies wood were studied by Kord (2011). Results indicated that flexural properties and impact strength of PP/WF composites decreased with increasing bark flour loading (Table 4). Some other plastics which have processing temperature lower than $200^{\circ} \mathrm{C}$, such as acrylonitrile butadiene styrene (ABS) and polystyrene (PS), have not been widely used in WPCs due to their limited ductility (impact strength $<35 \mathrm{~J} / \mathrm{m}$ and elongation at break $<2.5 \%$ ). Fillers that exist in the polymer act as stress concentrators and can decrease the impact strength of plastics (Yeh 2007). ABS may have more opportunities in WPCs due to its hydrophilic nature, and its mechanical properties are much better than those of HDPE, PVC, and PP. The problem here is that cost of ABS is higher than that of the other plastics (Griswold 2006).

Table 4. Summary of material properties for WPC (assuming a 50 or $60 \%$ WF) (Gardner and Murdock 2002)

\begin{tabular}{cccccc}
\hline Matrix & $\begin{array}{c}\text { Flexural MOE } \\
\text { (mm psi) }\end{array}$ & $\begin{array}{c}\text { Flexural MOR } \\
\mathbf{( p s i )}\end{array}$ & $\begin{array}{c}\text { Tensile } \\
\text { strength (psi) }\end{array}$ & $\begin{array}{c}\text { Shear } \\
\text { strength (psi) }\end{array}$ & $\begin{array}{c}\text { Hardness } \\
\text { (Ibs) }\end{array}$ \\
\hline PE & $0.1-0.26$ & $1500-3700$ & $200-2200$ & $200-800$ & N/A \\
PP & $0.6-0.8$ & $4,000-5,000$ & $1700-1800$ & $1300-1400$ & 3,000 \\
PVC & $0.7-0.8$ & $5,000-6,000$ & $3,000-4,000$ & $1500-1700$ & 2500 \\
\hline
\end{tabular}

\subsection{Coupling Agents}

The chemical structure of cellulose contains enormous amounts of hydroxyl groups. These hydrophilic hydroxyl groups absorb water molecules easily and swell the wood fiber (Wang 2007). As shown, the hydroxyl groups on different wood fibers form hydrogen bonds and, as a result, WF aggregates easily. Chemical "coupling" or "compatibilizing" agents have been employed to improve the dispersion, adhesion between wood fibers and thermoplastic matrices in production and affinity (Kim et al. 2006). Chemical coupling agents are polymers used in small quantities to treat a surface so that bonding occurs between it and other surfaces, e.g., WF and thermoplastics. Coupling agents contain polar and non-polar groups that can react or interact with hydroxyl groups of WF and thermoplastics. They could reduce the surface energy of WF and alter it to non-polar, more similar to the plastic matrix (Rude 2007). They act as linkages that connect WF and thermoplastics by forming covalent bonds and secondary bonding (such as hydrogen bonding) (Rude 2007). Coupling agents promote the adhesion and the dispersion of WF in the thermoplastics polymer matrix, besides improving mechanical properties (Sihombing et al. 2012). Therefore, chemical treatments can be considered to modify WF properties (Yang et al. 2014). 


\subsubsection{Silanes coupling agents}

Silanes are efficient coupling agents that are extensively used in WPCs and adhesive formulation. Xie et al. (2010) considered Silanes (Trialkoxysilanes) as the most useful and effective coupling agent because it forms strong covalent bonds with wood-OH groups. The addition of Trialkoxysilanes to the matrix can improve the interfacial adhesion between WF and thermoplastics polymer matrix and enhance the resulting WPCs' exterior mechanical performance (Xie et al. 2010). The incorporation of Trialkoxysilanes increases the crystallinity of the composites (Salmah et al. 2007). Metin et al. (2004) used 3- aminopropyltriethoxysilane (AMPTES), methyltriethoxysilane (MTES), and 3- mercaptopropyltrimethoxysaline (MPTMS) at four different concentrations $(0.5-2 \mathrm{wt} \%)$ in PP based WPCs. Saline treatment showed significant enhancements in the mechanical properties of the WPCs. SEM studies also exhibited better dispersion of saline-treated filler particles in the PP matrix.

\subsubsection{Maleic anhydride polypropylene (MAPP)}

MAPP is one of the coupling agents used in the WPCs because of its availability and ability to enhance WPCs' properties ( $\mathrm{Li}$ et al. 2007). Cellulose-MAPP copolymers provide a covalent bond across the interface in the WPCs. Ashori and Nourbakhsh (2011) used MAPP as a coupling agent for the surface modification of poplar WF. It was found that the use of 5 and $7.5 \mathrm{wt} \%$ of MAPP leads to better interaction, decreases in the water absorption, and slow penetration of moisture in the composites. Asgary et al. (2013) studied the effect of MAPP coupling agent on the old newsprint/PP nanocomposites. The authors observed that $3 \mathrm{wt} \%$ loadings of MAPP in the composites resulted in much greater mechanical properties than the samples without MAPP. It was also found that WPCs with $3 \mathrm{wt} \%$ MAPP significantly improve flexural strength and modulus compared to the control. The tensile strength of pure PP was improved when MAPP was added.

Researchers have also investigated the influence of the incorporation of MAPP as a coupling agent on the properties of jute/PP-based WPCs (Doan et al. 2006). They observed that $2 \mathrm{wt} \%$ MAPP addition to PP matrix could significantly enhance the adhesion strength with jute fibers and in the mechanical properties of WPCs. Khalid et al. (2006) have investigated the use of MAPP as a coupling agent for the PP-oil palm empty fruit bunch fiber (OPEFB) based WPCs. The incorporation of $2 \mathrm{wt} \%$ MAPP concentrations gives the best result for the PP-OPEFB based WPCs. There was a significant increase in tensile and impact strength of PP-OPEFB based WPCs than the control sample. However, further loading of MAPP from 2 to $7 \mathrm{wt} \%$ decreased the tensile and impact properties of WPCs. Ndiaye and Tidjani (2012) studied the effect of MAPP addition into oxidized polypropylene (OPP) on the thermal properties of WF/PP-based WPCs. They observed that $3 \mathrm{wt} \%$ MAPP loading in the composites improved the thermal behavior of the composites than the OPP coupling agent.

In another study, Zhou et al. (2013) used MAPP as a coupling agent to study the effect of coupling agent on the rheological behavior of bamboo powder-PP foamed composites. The incorporation of MAPP in WPCs enhanced the rheological behavior of bamboo powder-PP-based WPCs. Fourier-transform infrared spectroscopy (FTIR) and X-ray spectrometry (XRS) results revealed that the interfacial compatibility of the MAPP-treated composites was enhanced. X-ray diffraction analysis (XRD) results showed that the degree of crystallinity increased from $21.05 \%$ to $26.52 \%$ after modification with MAPP. 


\subsection{Wood-Plastic Composites Prepared with Nanofillers}

Nanoparticles or nanofillers are presently considered materials with great potential as fillers for the amendment of physical and mechanical properties of WPCs (Njuguna et al. 2008). The term nanometer is used to define nanometer-scale items $\left(10^{-9} \mathrm{~m}\right)$. A nanometer is equivalent to a billionth of a meter, nearly 80,000 times thinner than a human hair. The nanometer is smaller than the wavelength range of visible light but larger than many atoms (Kamel 2007). As the nano-scale fillers are generally free from defects, their application in the field of composites set up new trends to overwhelm the limitations of the conventional micrometer scale (Azeredo 2009). Nanofillers offer a larger effective surface area than microfillers. As a result, there is more interphase region in nanocomposites than in micro composites (Schadler et al. 2007). Nanofillers have high aspect ratios thus show better reinforcement for WPCs manufacturing (Magaraphan et al. 2001).

\subsubsection{Graphene}

Graphene is made by single layer of carbon atoms and bonded by $\mathrm{SP}^{2}$ orbitals into hexagonal two-dimensional crystal lattice allotrope of carbon (Sheshmani and Ashori 2013). The fabrication of WPCs using Graphene nanoplatelets (GNPs) was studied by Sheshmani and Ashori (2013). The influences of GNPs as a reinforcing agent on the physical, mechanical, and thermal properties of WPCs were studied. The addition of GNPs moderately increased the impact strength of WPCs. Tensile and flexural properties of WPCs reached their maximum values when $0.8 \mathrm{wt} \%$ GNPs were added. The incorporation of GNPs also reduced the average WA and thickness swelling by $35 \%$ and 30\%, respectively, compared to the WPCs without GNPs. WPCs filled with GNPs degraded at a higher temperature compared to PP-based WPCs and control samples.

In another study, Chaharmahali et al. (2014) explored the influence of GNPs on the mechanical and physical properties of PP-based WPCs. The tensile and flexural properties reached maximum values when $0.1 \mathrm{wt} \%$ of GNPs was added, while the notched impact strength was slightly decreased. Adding GNPs did not change the average WA and thickness swelling (TS) compared to the control WPCs. Yue et al. (2014) mixed carbon nanotubes (CNTs) and GNPs into an epoxy matrix at different ratios and studied the effect of CNTs and GNPs ratios on the properties of the WPCs. The combination of CNTs and GNPs synergistically increased flexural properties and decreased the electrical percolation threshold for the WPCs.

\subsubsection{Carbon nanotubes (CNTs)}

CNTs are among the most studied nanomaterials due to their unique functional properties such as good mechanical strength, high chemical, and water-resistance as well as high thermal and electrical conductivity (Kordkheili et al. 2012). CNTs have gained huge application in most of the areas of science and technology and have been widely used as reinforcement in polymer, wood, and cement-based composites. CNTs have two types, single cylindrical walls carbon nanotubes (SWCNTs) and multiple walls carbon nanotubes (MWCNTs) (Kordkheili et al. 2013).

Mechanical and physical properties of experimental composites fabricated from LDPE, WF, and SWCNTs were studied by Kordkheili et al. (2013). It was found that the WA and TS of the composites reduced with the increased amount of SWCNTs from 1 to $3 \mathrm{wt} \%$ and (Maleic anhydride polyethylene) MAPE (3 wt $\%$ ) in the composites. The mechanical properties of LDPEbased WPCs were significantly enhanced with the higher addition of CNTs and MAPE in the 
composites. WPCs containing $2 \mathrm{wt} \%$ of SWCNTs and $3 \mathrm{wt} \%$ of MAPE showed the highest impact strength.

In another study, Asgary et al. (2013) investigated the effect of multi-walled carbon nanotubes (MWCNTs) as a reinforcing agent on the physical and mechanical properties of old newsprint (ONP)/PP composites. The results of strength measurement indicated that Izod impact strength improved significantly when $1.5 \mathrm{wt} \%$ MWCNTs was loaded while flexural and tensile properties reached their maximum when $2.5 \mathrm{wt} \%$ MWCNTs was added in the composites. Both physical and mechanical properties were improved when $3 \mathrm{wt} \%$ MAPP coupling agent was applied. In this work, MWCNTs were compounded with PVC, WF (Populus deltoides WF), and foaming agent in an internal mixer by Farsheh et al. (2011). The results indicated that because of MWCNTs, the density of foamed composites was not affected by the chemical foaming agent. Tensile strength and modulus were increased by up to $20 \%$ and $23 \%$, respectively. Also, WA and thickness swelling were decreased as compared with control samples (without MWCNTs).

Ashori et al. (2012) investigated the effects of MWCNTs as a reinforcing agent on the mechanical and physical properties of bagasse/HDPE composites. MAPE was added as a coupling agent. The authors are of the opinion that tensile and flexural properties were improved when 1.5 $\mathrm{wt} \%$ MWCNTs were added. The incorporation of MWCNTs reduced the mechanical properties and WA of the composites. Both physical and mechanical properties were enhanced with the incorporation of $4 \mathrm{wt} \%$ MAPE. Kordkheili et al. (2012) developed cement composites from MWCNTs and bagasse fibers and evaluated the mechanical and physical properties of experimental cement panels. The results of measurement showed that panels having $0.5 \mathrm{wt} \%$ MWCNTs exhibited the highest impact strength and flexural modulus. WA and thickness swelling reduced with the increasing amount of MWCNTs in the composites.

\subsubsection{Nanoclay}

Nanoclays are layered mineral silicates with nanometer size. Nanoclays are produced by the disintegration and chemical decomposition of rocks with particle sizes less than 2 microns. Nanoclays are organized into several classes such as montmorillonite (MMT), bentonite, kaolinite, hectorite, and halloysite based on their morphology and chemical decomposition (Singh-Beemat and Iroh 2012). MMT is among the widely used reinforcement for nanoclay-polymer composites (Yadav et al. 2020).

The substantial increase in the mechanical properties with the addition of less amount of nanofiller $(<10 \mathrm{wt} \%)$ is one of the main advantages of using nanoclay particles in a polymer matrix (Chavooshi et al. 2014). Lee et al. (2008) mixed nanoclay (Cloisite ${ }^{\circledR}$ 15A) into WF/PP-based WPCs in the presence of MAPP coupling agent. They found that the incorporation of nanoclay increased the thermal stability of the WPCs. Tensile strength and modulus indicated maximum values when $3 \mathrm{wt} \%$ nanoclay was loaded in the composites.

The influence of nanoclay (Cloisite ${ }^{\circledR} 20 \mathrm{~A}$ ) and MAPP loading on the mechanical properties and WA of PP/WF (Poplar WF) based WPCs were examined by Ashori and Nourbakhsh (2011). The maximum tensile and flexural strength (increased by $46 \%$ compared to the pure PP) were achieved in the composites when $3 \mathrm{wt} \%$ nanoclay and $7.5 \mathrm{wt} \%$ MAPP were added. It was also found that the incorporation of nanoclay lowered the WA of WPCs. Another study by Chavooshi et al. (2014) studied the effect of nanoclay (Cloisite ${ }^{\circledR} 15 \mathrm{~A}$ ) incorporation, such as $0 \%, 2 \%, 4 \%$, and $6 \%$, on long-term mechanical and physical properties of PP/Medium density fiberboard 
(MDF) dust based WPCs. The results revealed that long-term WA and thickness swelling (TS) decreased as the nanoclay content increased. Maximum withdrawal strength of fasteners (screws and nails) was obtained in the samples reinforced with $2 \mathrm{wt} \%$ nanoclay.

Kord and Kiakojouri (2011) explored the effect of nanoclay (Cloisite 30B) dispersion on the mechanical and physical properties of PP/WF (beech tree WF)/glass fiber composites. They determined that the tensile properties of composites increased with the increase of nanoclay up to $4 \mathrm{wt} \%$ and then decreased. However, the water uptake and impact strength of composites reduced with increasing the nanoclay contents. Long-term WA behavior of PP/WF (beech tree WF)/nanoclay (30B) hybrid nanocomposites was evaluated by Ghasemi and Kord (2009), In the presence of MAPP coupling agent. The result showed that the WA reduced by increasing nanoclay and MAPP (4 wt $\%$ ) contents. The mechanism of WA of the composites followed under the study of the kinetics of a Fickian diffusion process. Deka and Maji (2010) blended HDPE, LDPE, PP, and PVC (in the ratio of 2:2:2:1) with Nals (Phragmites karka) WF and different contents of nanoclay to determine the effect compatibilizer and nanoclay on the properties of polymer blend/WF composites. Polyethylene co-glycidyl methacrylate (PE-co-GMA) was used as a compatibilizer. Composites incorporated with $3 \mathrm{wt} \%$ nanoclay and $5 \mathrm{wt} \%$ compatibilizers showed the highest mechanical properties. Hardness, thermal stability, and water uptake improved significantly with the loading of nanoclay to polymer/WF composites.

Chemical foaming agents, such as Azodicarbonamide (AZD) and nanoclay (Cloisite 15A) content affected the mechanical-physical and foaming properties of HDPE/wheat straw flour (WSF) based WPCs (Babaei et al. 2014). Increasing the AZD content from 2 to 4 phr (parts per hundred) increased the average cell density and size, whereas the foam density exhibited a reduction to $21.7 \%$, and by adding nanoclay up to $5 \mathrm{phr}$, the cell size reduced, and density increased. The WA and TS were getting higher to $19.3 \%$ and $26.5 \%$, respectively when the AZD contents increased from 0 to $4 \mathrm{phr}$. The mechanical properties of HDPE/WSF composites were decreased by loading AZD, and it was improved by incorporating $2 \mathrm{phr}$ of nanoclay.

Alamri and Low (2013) exploited the fact that moisture affects the mechanical properties of nanoclay (30B) filled with recycled cellulose fiber (RCF) reinforced epoxy hybrid WPCs. The incorporation of $5 \mathrm{wt} \%$ nanoclay reduced the WA of RCF/epoxy-based WPCs. Exposure to moisture for a long time resulted in a significant reduction in flexural strength, flexural modulus, and fracture toughness due to the decomposition of the fiber-matrix interface. The presence of nanoclay slightly reduces the effect of moisture on the mechanical properties.

\subsubsection{Nanoclay modification}

The hydrophilic nature of nanoclays and hydrophobic behavior of thermoset/thermoplastic polymers are not compatible in their original states. Therefore a modification of either the nanoclay or polymer is essential for intercalation, exfoliation and dispersion of nanoclay in the polymer matrix. Surface modification of nanoclay is an option that has widely been used to obtain greater compatibility of the polymer and nanoclay. The ion exchange method is a way to modify the surface of nanoclay by exchanging $\mathrm{Na}^{+}$or $\mathrm{Ca}^{2+}$ gallery cations in nanoclay with alkylammonium ions. The organic treatment is usually carried out through ion exchange between inorganic sodium cations on the clay surface with the desired organic cation that is more reactive such as the primary, secondary, tertiary, and quaternary octadecylamine cations (Lubis and Park 2020). In the ion exchange process, the inorganic (sodium) ions are exchanged with more voluminous organic 
onium cations, and it results in widening the gap between the single sheets. The polymeric movements are enabled through this, and the properties of every single sheet are altered from being hydrophilic to hydrophobic.

Alkylammonium or alkylphosphonium cations in organic silicates (OLS) help to reduce the surface energy of the inorganic host and enhance the wettability and exfoliation with the polymer matrix, which eventually results in larger interlayer spacing. Furthermore, functional groups of alkylammonium or alkylphosphonium cations can react with the polymer matrix, or in some cases, initiate the polymerization to enhance the strength of the interface between the inorganic and the polymer matrix. There are several types of modification that can be done, such as treating the silicates with transition metal ions or clay surface treatments using quaternary ammonium salts (Yadav et al. 2020).

Organically modified MMT with dodecylammonium chloride to synthesis polymer/nanoclay composites has been reported in published work (Lubis and Park 2020). This modification of the clay surface leads to an increase of around $75 \%$, from $10.33 \mathrm{~A}^{\circ}$ to $18.21 \mathrm{~A}^{\circ}$, of the distance between silicate interlayers. The thermal properties and stability of the nanocomposites are also improved. The organophilic nature of the nanoclay can be altered into an organophobic one with the introduction of small molecular weight alkyl chain ions. The octadecyl ammonium cations are about $2.4 \mathrm{~nm}$ in length, fully extended, and replace the exchangeable cations in the nanoclay galleries. The exchange rate of the cations by organic modifiers is around 95-98\%. This resulted in about one organic modifier for every square nanometer, showing that nanoclay gallery spaces were successfully intercalated with dodecylamine. The addition of dodecylamine to the silicate layers has been reported to enhance clay swelling in the HDPE matrix.

\section{Fabrication Processes of WPCs}

The manufacturing of WPCs is followed by extrusion, injection molding, compression molding, and pultrusion (Gebhardt 2011). Drying of wood fibers or wood flour is an important prerequisite of WPCs production since the water content of wood will affect the processing and final product quality of WPCs significantly.

\subsection{Extrusion Process}

The extrusion process is the main process in the WPC manufacturing system. The objective of extrusion is to melt the polymer matrix and to mix the polymer, wood flour/wood fibers, and additives in a process called compounding. The extruder conveys the compounded wood-polymer mixture through the die. There are four types of extrusion systems mainly used in WPC manufacturing, namely (1) single screw, (2) co-rotating twin-screw, (3) counter-rotating twinscrew, and (4) Woodtruder (Gardner et al. 2015). The extrusion process was based on drying of wood flour (pine WF) to reach a moisture content of $0.03 \%$ (Bengtsson and Oksman 2006). As an example, the dried WF and HDPE granules were fed to the co-rotating twin-screw extruder at a temperature varying from 165 to $200^{\circ} \mathrm{C}$. At the end of the extruder, a rectangular die was used, and the extrudates were then cooled at ambient temperature. During the extrusion process, silane was added to improve the product properties.

Manufacturing of WPCs from HDPE, WF (oak), and glass fibers using a twin-screw extruder was done by Zolfaghari et al. (2013). The result exhibited an outstanding improvement in all mechanical properties of extruded WPCs. In another study, a twin-screw extruder was used 
to mix HDPE with up to $70 \mathrm{wt} \%$ wood flakes (pine) in WPC manufacturing (Balasuriya et al. 2001). The high tensile and flexural strength of twin-screw compounded composites showed that melt mixing is a better processing method than mechanical blending. The melt mixing enhanced flake wetting and consequently increased the mechanical properties of the WPCs.

Owing to periodic and desorption of moisture, WPCs can undergo cyclic dimensional alteration. The resulting loss of mechanical integrity can be improved by adding a coupling agent. A twin-screw extruder can be used as another solution to produce PP-based WPCs (Yeh and Gupta 2008). The mechanical properties were seen to be similar at a $40 \mathrm{wt} \%$ wood content. But using high screw rotation speeds and long residence time decreased the rates of WA even in the absence of a coupling agent (Table 5).

Table 5. Rate of water absorption (WA) of and equilibrium moisture content (EMC) of WPCs (Yeh and Gupta 2008)

\begin{tabular}{ccccc}
\hline $\begin{array}{c}\text { PP-g-MA to } \\
\text { wood (wt\%) }\end{array}$ & $\begin{array}{c}\text { Co-rotation } \\
\text { speed (rpm) }\end{array}$ & Pass & $\begin{array}{c}\text { Rate of WA } \\
(\mathbf{w t \%} / \mathbf{d a y})\end{array}$ & $\begin{array}{c}\text { EMC } \\
\mathbf{( w t \% )}\end{array}$ \\
\hline 0 & 85 & 1 & $0.234(0.001)$ & $12.81(0.01)$ \\
0 & 85 & 2 & $0.203(0.002)$ & $12.57(0.06)$ \\
0 & 150 & 1 & $0.141(0.0005)$ & $11.25(0.03)$ \\
2 & 85 & 1 & $0.099(0.001)$ & $12.02(0.03)$ \\
2 & 85 & 2 & $0.090(0.001)$ & $11.87(0.02)$ \\
2 & 150 & 1 & $0.068(0.001)$ & $10.76(0.01)$ \\
4 & 85 & 1 & $0.081(0.001)$ & $12.06(0.03)$ \\
4 & 85 & 2 & $0.068(0.0003)$ & $11.84(0.0002)$ \\
4 & 150 & 1 & N/A & N/A \\
\hline
\end{tabular}

\subsection{Compression Molding Process}

The compression molding process is a molding method in which preheated polymer and cellulosic material are molded into a heated mold cavity. A top plug and pressure are applied to force the materials to contact all areas of the mold. Throughout the process, the pressure and heat are maintained until the polymer reached the curing state. Compression molding has been utilized and investigated for many years in the manufacture of automobile composite parts (Holbery and Houston 2006). The compounding step can be eliminated, thus mixing and molding can be performed in one step in the compression molding process (Jayaraman 2003). This will minimize the length reduction of the fibers and lower the compression time of fibers at elevated temperatures. Using this method, the cellulosic fibers get distributed evenly between polymer films, and then the WPCs are created by pressing in a compression molder at sufficient time and temperature.

The compression molding process has been used to produce WPCs from wetlaid lyocell, wood flour, and PP (Johnson et al. 2008). Lyocell fiber-PP-based WPCs that manufactured with compression molding process revealed comparable tensile and flexural properties as meltprocessed (injection-molded) rayon-reinforced PP composites. However, the unsolved and often studied problem during compression molding is the reorientation of the fibers during processing. The formation of the surface void is still a major drawback, particularly for the automotive 
industry. Such voids need further treatment to obtain a good appearance after painting (Odenberger et al. 2004). It is essential to understand the mechanism of reorientation since the final fiber orientation and distribution have a strong influence on the strength properties. A properly designed mold can ensure greater unidirectional alignment avoiding void formations.

\subsection{Injection Molding Process}

Production of WPCs parts containing complex geometries and requiring no finishing step always involves the injection molding process. An example of WPCs injection molded part is a post cap for guard rail structures. The injection molding process for WPCs has gained limited focus research compared to the extrusion process, but the topics tend to be identical and focus on material compositions and properties (Kuo et al. 2009). There have also been reports examining injection molding to produce WPCs microcellular foams (Gosseling et al. 2006) as well as injection molding to produce WPCs made of biopolymers (Sykacek et al. 2009).

Karmaker and Youngquist (1996) manufactured composites from PP and jute fibers using the injection molding technique. Injection molding caused high fiber attrition resulting in an average fiber length of 390 and $350 \mu \mathrm{m}$ for compositions with and without coupling agent. Migneault et al. (2009) examined the effects of the processing method on the structure and properties of WPCs. Composites were manufactured using both extrusion and injection molding techniques. The injection molding technique resulted in better composite mechanical and physical properties than the extrusion technique, but higher density was obtained with the extrusion process. In this study, foamed WPC based on post-consumer HDPE/PP (85:15) blends and yellow birch wood fibers were injection molded to evaluate the relation between the processing condition and final morphology. Microscopic analysis indicated that skin thickness and cell size increased significantly with wood content but were relatively unaffected by mold temperature. In contrast, actual fiber length was decreased during processing (Gosseling et al. 2006).

A comparison between extrusion and injection molding processes for producing WPC has been explored by (Migneault et al. 2009). Both processes use screws to convey, pump, and blend the mixed component. It is also found that melting, shaping, and cooling are the common steps in both extrusion and injection molding processes. However, the process parameters such as residence time, temperature, pressure, shear rate, shear stress, and cooling rate are different between extrusion and injection molding processes. Moreover, the pressure and shearing in injection molding are higher than en extrusion regardless of the process parameters. WPCs composed of 50\% WF and HDPE have been produced from extrusion and injection molding and exhibited the same flexural modulus (Stark et al. (2004). However, the density and flexural strength of injected parts were higher. The study reported that this could be resulted by enhancing interfacial contact in injection molding between wood and polymer, encapsulating wood particles within the polymer matrix, and resulting in higher density and greater strength.

Concerning physical properties, Clemons and Iback (2004) conducted a moisture sorption behavior comparison for WPC, composed of 50\% of 40-mesh pine flour and HDPE, and concluded that water-soaked extruded samples absorbed and swelled more water than injection molded samples. 


\subsection{Pultrusion Process}

A WPCs profile is produced by pulling material through a stationary die in the pultrusion process. The process consists of entrance and final sections, which are tapered to the size of the final dimension of the profile. Briefly, the raw material enters the constant geometry section, where the polymer is melted. The blended materials then pass through a cooling section where the thermoplastic polymer hardens. The main requirement of a pultrusion process is that the blended material is capable of flowing through the die. Therefore a consistent product is produced after pultrusion (WRAP 2003).

\section{Challenges for Wood-Polymer Composites}

\subsection{Interphase}

The prime disadvantage encountered while the loading of natural fibers or any lignocellulosic materials into a thermoset/thermoplastic matrix is the weak interfacial bonding between the components, which results in low physical, mechanical, and thermal properties of WPCs. Generally, natural fibers have polar hydroxyl groups on its surface, which creates a difficulty to form a well bonded interphase with a relative nonpolar matrix. There are two major approaches to improve bonding between natural fibers and matrix (Kordkheili et al. 2012). On the one hand, the natural fibers can be treated with acetylation, silane treatment, heat treatment, and treatment with sodium hydroxide to improve the internal bonding. Furthermore, the incorporation of nanoparticles, such as nanoclay and CNTs, improves the internal bonding as well as overall properties of WPCs because of their high surface area, high Young modulus, and low density (Lei et al. 2015).

\subsection{Moisture Absorption}

Moisture absorption is widely recognized as one of the main reasons for the long-term failure of wood-polymer composites when exposed to the atmosphere or in contact with an aqueous media. Natural fibers are made of cellulose, hemicellulose, and lignin, and it has pores on its surface. WA nature of natural fibers leads to undesirable effects on mechanical properties and dimensional stability of composites. Therefore, it is necessary to study the moisture uptake nature of natural fibers in order to estimate not only the durability of the wood-polymer composites insight the water but also the negative effects that the absorbed moisture may cause. Generally, moisture enters into the composites by three different mechanisms. Briefly, the first mechanism is a diffusion of water molecules into the nano and micro-gaps between the polymer chains. The second mechanism is the capillary transport of water into the gaps, which interfaces between the fiber and the polymer matrix owing to incomplete wettability and impregnation. The third mechanism involves the transport of micro-cracks in the matrix, formed either due to fiber swelling or during the compounding process (Clemons and Iback 2004).

\section{Properties of WPCs}

WPCs exhibit hybrid properties of plastic and wood. Generally, loading wood to a thermoplastic matrix improves the thermal and mechanical properties when compared to solid thermoplastics. In contrast, the addition of thermoplastic to the wood decreases the WA and swelling as compared to wood and traditional wood composites. 


\subsection{Mechanical Properties of WPCs}

The hardness of a material can be increased by enhancing its potential to deform plastically by means of initiating a very large number of microscopic events (Dobreva et al. 2006). The initiation of a large number of micro cracks by short fibers or inorganic particles, initiation of small plastic zones induced by stress concentration of particles, and cavitation at the surface of (or inside) particles are the way to enhance the hardness of materials. Low dispersion and weak adhesion of particles initiate a number of small and stable voids, thus allowing further deformation of the polymer matrix between the particles. Coupling agents such as MAPP can be incorporated to improve the interfacial bonding between cellulosic materials and a thermoset/thermoplastic polymer matrix (Balasuriya et al. 2001).

Dobreva et al. (2006) studied the mechanical and deformation mechanisms of PP/WF-based WPCs modified by styrene-butadiene rubber (SBR) in the presence of MAPP as an impact modifier and compatibilizer. The mechanical properties of WPCs can be improved remarkably with the addition of $10 \mathrm{wt} \%$ wood-loaded composites with $10 \mathrm{wt} \%$ MAPP, such as yield stress of $23.5 \mathrm{MPa}$, impact strength of $14.2 \mathrm{~kJ} / \mathrm{m}^{2}$, and young modulus $\left(\mathrm{E}_{11}\right)$ of $1220 \mathrm{MPa}$. In general, a higher stiffness of MAPP can improve the modulus of WPCs but cause a dramatic reduction in elongation at break.

Effects of wood fiber characteristics on mechanical properties of WF (pine WF)/PP composites were investigated Stark and Rowlands (2003). MAPP was used as a coupling agent. Wood flour particles (30, 70, 120, and 235 mesh) were compounded at $40 \mathrm{wt} \%$ with PP. They observed that the tensile and flexural properties were increased with increasing aspect ratios. Notched impact energy increased with increasing particle size, while unnotched impact energy reduced with increasing particle size. Grafting of $\mathrm{m}$-isopropenyl- $\alpha, \alpha$-dimethylbenzyl-isocyanate (m-TMI) onto isotactic PP in a twin-screw extruder can be used as a novel compatibilizer which consists of (m-TMI-g-PP) with an isocyanate functional group. The influence of filler concentration on the mechanical properties of WPCs that incorporated with m-TMI- $\alpha-P P$ compatibilizer was investigated by Karmarkar et al. (2007). The incorporation of compatibilizer indicated greater reinforcement of composites. Flexural and tensile properties of composites were increased by $85 \%$ and $45 \%$, respectively.

Bouafif et al. (2009) reported that the composites filled with higher wood fiber size produced higher strength and elasticity but lower energy to break and elongation. Increasing wood fiber load improved the strength and stiffness of the composites but reduced elongation and energy to break. In another study, Kuo et al. (2009) was evaluated the effects of material compositions on the mechanical properties of WPCs manufactured by injection molding. Using a ratio of WF (Cunninghamia lanceolata)/plastic matrix/MAPP/zinc stearate of 47:47:3:3, the tensile strength (TS) and modulus of rupture (MOR) of WPCs prepared from LDPE and PP were seen to be larger than those of LDPE and PP themselves. The MOR, TS, and storage modulus of WPCs prepared from PP mixed with 47\% WF and 3-4\% MAPP was larger than those of the other WPCs manufactured in this work.

The addition of flame retardants (magnesium hydroxide) in WF (poplar)/PP composites affects the mechanical properties of the composites. Marginal reduction in the mechanical properties of PP/WF composites was seen with the addition of flame retardants (magnesium hydroxide) (Sain et al. 2004). Espert et al. (2004) prepared natural fiber/PP composites and water uptake in them was studied by immersion of the samples in water at three different temperatures, 
23,50 , and $70^{\circ} \mathrm{C}$. A decrease in tensile properties of the composites was demonstrated, indicating a high loss in mechanical properties of the water-saturated samples than the dry samples.

\subsection{Physical Properties of WPCs}

New applications and end uses of WPCs for flooring, decking, outdoor facilities, window frames, and various construction materials, and their exposure to atmosphere or contact with aqueous media have made it essential to investigate the physical properties of these materials. Physical properties like WA, thickness swelling, biological resistance, flame retardancy, and density. Physical properties are generally connected to material structure and performances, so the measurement of physical property changes can be used to evaluate material structural changes. Physical properties are the most important characteristics of WPCs exposed to the environmental conditions that determine their end-use application (Markarian 2008).

Kamdem et al. (2004) studied some physical properties of WPCs made of recycled HDPE with and without CCA (Chromated copper arsenate) treated red pine WF. The authors found that the biological durability and the photo-protection were improved for samples loading CCA-treated WF. In their study, Ghasemi and Kord (2009) investigated the long-term WA of WPCs manufactured from PP/WF (Beech)/nanoclay (Cloisite ${ }^{\circledR}$ 30B)/MAPP. The long-term WA of the composites was evaluated by their immersion in water at room temperature for a long period (3000 h). The result showed that WA of composites reduced with increasing nanoclay content and adding MAPP (Table 6).

Table 6. Maximum water absorption for different formulations (Ghasemi and Kord 2009)

\begin{tabular}{lc}
\hline $\begin{array}{l}\text { Sample code } \\
\text { (PP/WF/MAPP/Nanoclay) }\end{array}$ & $\begin{array}{c}\text { Maximum water absorption } \\
(\mathbf{\%})\end{array}$ \\
\hline $50 \mathrm{P} / 50 \mathrm{~W}$ & 14.28 \\
$50 \mathrm{P} / 50 \mathrm{~W} / 2 \mathrm{M}$ & 14.05 \\
$50 \mathrm{P} / 50 \mathrm{~W} / 4 \mathrm{M}$ & 13.75 \\
$50 \mathrm{P} / 50 \mathrm{~W} / 3 \mathrm{~N}$ & 14.16 \\
$50 \mathrm{P} / 50 \mathrm{~W} / 2 \mathrm{M} / 3 \mathrm{~N}$ & 13.87 \\
$50 \mathrm{P} / 50 \mathrm{~W} / 4 \mathrm{M} / 3 \mathrm{~N}$ & 13.61 \\
$50 \mathrm{P} / 50 \mathrm{~W} / 6 \mathrm{~N}$ & 14.02 \\
$50 \mathrm{P} / 50 \mathrm{~W} / 2 \mathrm{M} / 6 \mathrm{~N}$ & 13.40 \\
$50 \mathrm{P} / 50 \mathrm{~W} / 4 \mathrm{M} / 6 \mathrm{~N}$ & 13.25 \\
\hline
\end{tabular}

The effects of species, wood type, and fiber size on the WA of WPCs were evaluated by Bouafif et al. (2009). Researchers found that the WA of WPCs slightly varied among species and increased with increasing fiber size but to a negligible extent as compared with other wood-based composites and solid wood. This study dealt with the fabrication of composites from sawdust and recycled polyethylene terephthalate (PET) at different ratios by a flat-pressed method. The water absorption and thickness swelling were measured after 24 hours of immersion in water at 25, 50, and $75^{\circ} \mathrm{C}$ temperature. It was seen that the water absorption and thickness swelling increased when PET content reduced in the composites and testing water temperature increased (Rahman et al. 2013). 
Ayrilmis et al. (2011) studied the effect of a thermal-treatment method on the dimensional stability of flat-pressed WPCs containing wood fiber (eucalyptus). The study that the WA and thickness swelling of WPCs samples significantly reduced with increasing treatment temperature and time. Jördens et al. (2010) employed time-domain spectroscopy (THz-TDS) to investigate the sorption of water into WPCs. The dielectric properties of the samples were determined for frequencies between 0.2 and $1.0 \mathrm{THz}$ for varying water contents. The result suggests that this technique is an ideal tool for a non-destructive, contactless determination of the water content. Stark et al. (2010) used oxygen index and cone calorimeter tests to study the fire performance of WF (pine)/PE composites and compared the results with unfilled PE and solid wood. Researchers then studied the effect of five additive-type fire retardants on the fire performance of WPCs. Ammonium polyphosphate and magnesium hydroxide highly improved the fire performance of WPCs as compared to bromine-based and zinc borate fire retardants.

The WA and decay resistance of HDPE-based WPCs manufactured from poplar, Douglasfir, black locust, white oak, and ponderosa pine were evaluated by Fabiyi et al. (2011). The dimensional stability of WPCs made from poplar was poor, whereas black locust performed well. However, Trametes versicolor (white rot) produced significantly higher weight losses on HDPE/poplar composites, while HDPE/Douglas-fir composites were less susceptible to this fungus. Alamri and Low (2013) evaluated the effect of WA on the mechanical properties of nanoclay (Cloisite ${ }^{\circledR}$ 30B) filled recycled cellulose fiber epoxy hybrid nanocomposites. The WA decreased as increased in the nanoclay content. Fracture toughness and flexural properties significantly decreased as a result of low WA. Interestingly, the impact toughness and impact strength were seen to increase after exposure to water.

A fire retardant (ammonium polyphosphate) and a light stabilizer (HALS) were added to improve the fire retardancy and durability of the composites. The fire retardant worsened the outdoor durability. However, WPCs with stabilized fire retarded indicated much lower fading than non-stabilized non-fire retarded composites (Garcia et al. 2009). Stark et al. (2004) have investigated the weathering characteristics of WF (Pandora pine)/HDPE composites. The samples were weathered in a xenon-arc weathering apparatus for 1,000, 2,000, and 3,000 h and then analyzed for color fade and loss of flexural strength. Results indicated that composites with a large wood component at the surface experienced a higher percentage of total loss in flexural strength after weathering.

\subsection{Morphological Properties of WPCs}

\subsubsection{Scanning Electron Microscopy (SEM)}

SEM is widely used to study morphology, structural and surface properties of fractured WPCs surfaces. SEM uses secondary electrons generated from either thermal or field emitting cathode (Segerholm 2007). SEM is an imaging technique for research where high-resolution images are important to be obtained for the analysis of morphological features. The SEM images of the fractured surfaces were usually used to analyze the interfacial features and predict the bonding strength (Ray et al. 2002). SEM images of the exposed surfaces of WPC specimens before and after broken are important for analysis, and the results are qualitatively correlated to the damage resulted from weathering process (Stark et al. 2004). Tong et al. (2014) manufactured WPCs from recycled HDPE and rice husk and studied the morphology of the composites. SEM micrographs exhibited better interfacial bonding between the fiber and polymer matrix. 


\subsubsection{Transmission Electron Microscopy (TEM)}

TEM is an important microscopy technique where a beam of electrons is transmitted through an ultra-thin specimen. An image is produced from the interaction of the electrons transmitted through the specimen. It is a widely used tool to determine the extent of intercalation or exfoliation of nanoclay in WPC. Nanoclay reinforced HDPE/WF (maple) composites were prepared by Faruk and Matuana (2008). They used TEM to study the degree of nanoclay intercalation in HDPEbased.

\subsubsection{Optical microscopy}

Traditional optical microscopy was often used to study the influences of environmental degradation on WPCs. The depth of the surface layer that has different colors from the core material was considered as the depth of degradation, and was measured from an optical microscopic image of a cross-section specimen (Lundin et al. 2001). Micro images of the exposed WPCs samples surfaces were evaluated to qualitatively characterize the degradation by the fungal attack (Clemons and Iback 2004).

\subsection{Thermal Properties of WPCs}

Thermal behavior and stability of the WPCs is a very important parameter for the processing and uses of WPCs. The manufacture of WPCs requires the mixing of WF and thermoset/thermoplastic polymeric matrix at elevated temperature, so the decomposition of the cellulosic materials can produce undesirable effects on the properties of WPCs. The most widely used techniques for thermal analysis are Thermogravimetric analysis (TGA) and Differential Scanning Calorimetry (DSC). Ndiaye and Tidjani (2012) have studied the effect of coupling agent (MAPP) on the thermal behavior of WF (pine)/PP composites. The thermal degradation behavior of the composites $\left(T_{m}, T_{p}\right.$, and $\left.T_{c}\right)$ was characterized by DSC. The result indicated that the degradation temperature of the composites shifted to slightly higher values after the addition of a coupling agent in the composites.

The effect of hexagonal boron nitride ( $\mathrm{h}-\mathrm{BN}$ ) on thermal properties of injection molded WPCs prepared from WF (poplar) and HDPE with $3 \mathrm{wt} \%$ coupling agent (MAPE) was evaluated by Ayrilmis et al. (2014). The DSC analysis showed that the crystallinity, melting enthalpy, and crystallization enthalpy of WPCs increased with increasing h-BN content. Farhadinejad et al. (2012) introduced nano wollastonite in WF/PP-based WPCs to investigate the effect of nano wollastonite on the thermal properties of WPCs. Thermal properties of the WPCs were characterized by different techniques such as TGA, DSC, limited oxygen index, and oxidative induction time. They observed that the introduction of nano wollastonite increased thermal stability as well as crystallinity in the composites because of the high specific area of nano wollastonite.

In another work, 30\% particles of iron wood (Xylia xylocarpa) were mixed with recycled polypropylene foam (RPPF) with two different additives glycerol as a plasticizer, and MAPP as a compatibilizer. The thermal behavior of composites was characterized by TGA. The result showed that composites containing plasticizer and compatibilizer had been shown a great influence on the thermal behavior of composites as compared to a composite without these additives (Tajan et al. 2008). Ratanawilai et al. (2012) determined the thermal properties of oil palm wood sawdust 
(OWS) reinforced post-consumer polyethylene composites using the TGA technique. It was found that the thermal stability of the composites slightly decreased with higher OWS content (Table 6). Gwon et al. (2010) prepared WPCs from PP, chemically treated WF and talc to investigate the thermal behavior of WPCs using the DSC technique. It was found that melting enthalpy was decreased by the addition of fillers because of the decreased amount of the crystallizable resin and the interference of the fillers for the crystallization process. Li et al. (2014) used bamboo charcoal (BC) to enhance the thermal property of LDPE/WF WPCs. Researchers used the TGA technique to analyze the thermal behavior of composites. They concluded that the addition of BC improved $30 \%$ and $50 \%$ wt loss temperature.

Table 6. Weight percentage of OWS/PCR-HDPE composites at different temperatures (Ratanawilai et al. 2012)

\begin{tabular}{cccc}
\hline \multirow{2}{*}{$\begin{array}{c}\text { Temperature } \\
\left({ }^{\circ} \mathbf{C}\right)\end{array}$} & OWS (30\%) & OWS (40\%) & OWS (50\%) \\
\cline { 2 - 4 } & 98.8 & 98.4 & 97.7 \\
200 & 98.4 & 97.8 & 96.9 \\
300 & 93.4 & 91.5 & 89.2 \\
400 & 80.9 & 74.0 & 67.7 \\
500 & 38.8 & 36.2 & 34.5 \\
600 & 9.6 & 11.8 & 14.4 \\
\hline
\end{tabular}

\section{Conclusions}

The selection of polymer matrix is the most important factor in the development of WPCs. The selected polymer matrix should be available at low cost, good in performance, and nonhazardous to the environment. PP is widely used in WPC because of its better properties and availability. PP has a slightly higher stiffness than HDPE. The higher strength and stiffness of wood fibers/flour make them good candidates as plastic reinforcements. However, the thermal instability nature of WF places an upper limit on the processing temperature. Other intrinsic properties such as quality variation and low resistance to moisture also limit the applications of WF. The most important problem is the low compatibility between the hydrophilic WF and thermoset/thermoplastic polymeric matrices, which results in non-uniform dispersion of fibers within the matrix and poor mechanical properties. As a way to improve compatibility between WF and thermoset/thermoplastic polymeric matrices, coupling agents, such as MAPP and silane, have been employed. Coupling agents are polymers that are used in small quantities to treat a surface so that bonding occurs between it and other surfaces. MAPP coupling agent is popular in research and industry because of its effectiveness and availability. Nanoparticles or nanofillers are presently considered as great potential filler materials for the amendment of mechanical and physical properties of wood-plastic composites. Nano-scale filler offers a larger effective surface area than micro-scale filler. As a result, there is more interphase region in nanocomposites than in micro composites. Among all nanofillers, nanoclays are widely used as nanofiller in WPCs because it is eco-friendly, readily available in large quantity and inexpensive. Manufacturing methods like compression molding, pultrusion have some limitations. Extrusion and injection molding are the most widely used manufacturing processes in WPC due to their effectiveness. 


\section{Acknowledgments}

The authors are grateful for the support from the Department of Forest Products and Utilization, Forest College and Research Institute Hyderabad, India, and Research Center for Biomaterials, Indonesian Institute of Sciences (LIPI), Indonesia.

\section{References}

Alamri, H., and Low, I. M. 2013. Effect of Water Absorption on the Mechanical Properties of Nanoclay Filled Recycled Cellulose Fibre Reinforced Epoxy Hybrid Nanocomposites. Composites Part A: Applied Science and Manufacturing 44(1): 23-31. DOI: 10.1016/j.compositesa.2012.08.026

Al Maadeed, M. A., Ouederni, M., and Noorunnisa Khanam, P. 2013. Effect of Chain Structure on the Properties of Glass Fibre/Polyethylene Composites. Materials and Design 47: 725730. DOI: 10.1016/j.matdes.2012.11.063

Antov, P., Savov, V., and Neykov, N., 2017. Utilization of Agricultural Waste and Wood Industry Residues in the Production of Natural Fiber-Reinforced Composite Materials. International Journal-Wood, Design, and Technology 6: 64-71.

Arao, Y., Nakamura, S., Tomita, Y., Takakuwa, K., Umemura, T., and Tanaka, T. 2014. Improvement on Fire Retardancy of Wood Flour/Polypropylene Composites using Various Fire Retardants. Polymer Degradation and Stability 100(1): 79-85. DOI: 10.1016/j.polymdegradstab.2013.12.022

Asgary, A. R., Nourbakhsh, A., and Kohantorabi, M. 2013. Old Newsprint/Polypropylene Nanocomposites using Carbon Nanotube: Preparation and Characterization. Composites Part B: Engineering 45(1): 1414-1419. DOI: 10.1016/j.compositesb.2012.07.009

Ashori, A. 2008. Wood-Plastic Composites as Promising Green-Composites for Automotive Industries! Bioresource Technology 99(11): 4661-4667. DOI: 10.1016/j.biortech.2007.09.043

Ashori, A., and Nourbakhsh, A. 2011. Preparation and Characterization of Polypropylene/Wood Flour/Nanoclay Composites. European Journal of Wood and Wood Products 69(4): 663666. DOI: 10.1007/s00107-010-0488-9

Ashori, A., Sheshmani, S., and Farhani, F. 2012. Preparation and Characterization of Bagasse/HDPE Composites using Multi-Walled Carbon Nanotubes. Carbohydrate Polymers 92: 865-871. DOI: 10.1016/j.carbpol.2012.10.010

Ayrilmis, N., Dundar, T., Kaymakci, A., Ozdemir, F., and Kwon, J. H. 2014. Mechanical and Thermal Properties of Wood-Plastic Composites Reinforced with Hexagonal Boron Nitride. Polymer Composites 35(1): 194-200. DOI: 10.1002/pc.22650

Ayrilmis, N., Jarusombuti, S., Fueangvivat, V., and Bauchongkol, P. 2011. Effect of ThermalTreatment of Wood Fibres on Properties of Flat-Pressed Wood Plastic Composites. Polymer Degradation and Stability 96(5): 818-822. DOI: 10.1016/j.polymdegradstab.2011.02.005

Azeredo, H. M. C. D. 2009. Nanocomposites for Food Packaging Applications. Food Research International 42(9): 1240-1253. DOI: 10.1016/j.foodres.2009.03.019

Babaei, I., Madanipour, M., Farsi, M., and Farajpoor, A. 2014. Physical and Mechanical Properties of Foamed HDPE/Wheat Straw Flour/Nanoclay Hybrid Composite. Composites Part B: Engineering 56: 163-170. DOI: 10.1016/j.compositesb.2013.08.039

Bakraji, E. H., and Salman, N. 2003. Properties of Wood-Plastic Composites: Effect of Inorganic 
Additives. Radiation Physics and Chemistry 66(1): 49-53. DOI: 10.1016/S0969806X(02)00262-1

Balasuriya, P. W., Ye, L., and Mai, Y. 2001. Mechanical Properties of Wood Fake-Polyethylene Composites. Part I: Effects of Processing Methods and Matrix Melt Flow Behaviour. Composites Part A: Applied Science and Manufacturing 32(5): 619-629. DOI: 10.1016/S1359-835X(00)00160-3

Bengtsson, M., Gatenholm, P., and Oksman, K. 2005. The Effect of Crosslinking on the Properties of Polyethylene/Wood Flour Composites. Composites Science and Technology 65(10): 1468-1479. DOI: 10.1016/j.compscitech.2004.12.050

Bengtsson, M., and Oksman, K. 2006. Silane Crosslinked Wood Plastic Composites: Processing and Properties. Composites Science and Technology 66(13): 2177-2186. DOI: 10.1016/j.compscitech.2005.12.009

Bhaskar, J., Haq, S., Pandey, A. K., and Srivastava, N. 2012. Evaluation of Properties of Propylene-Pine Wood Plastic Composite. Journal of Materials and Environmental Science 3(3): 605-612.

Bishay, I. K., Abd-El-Messieh, S. L., and Mansour, S. H. 2011. Electrical, Mechanical and Thermal Properties of Polyvinyl Chloride Composites Filled with Aluminum Powder. Materials and Design 32(1): 62-68. DOI: 10.1016/j.matdes.2010.06.035

Bouafif, H., Koubaa, A., Perré, P., and Cloutier, A. 2009. Effects of Fiber Characteristics on the Physical and Mechanical Properties of Wood Plastic Composites. Composites Part A: Applied Science and Manufacturing 40(12): 1975-1981. DOI: 10.1016/j.compositesa.2009.06.003

Chaharmahali, M., Hamzeh, Y., Ebrahimi, G., Ashori, A., and Ghasemi, I. 2014. Effects of NanoGraphene on the Physico-Mechanical Properties of Bagasse/Polypropylene Composites. Polymer Bulletin 71(2): 337-349. DOI: 10.1007/s00289-013-1064-3

Chavooshi, A., Madhoushi, M., Navi, M., and Abareshi, M. Y. 2014. MDF Dust/PP Composites Reinforced with Nanoclay: Morphology, Long-Term Physical Properties and Withdrawal Strength of Fasteners in Dry and Saturated Conditions. Construction and Building Materials 52: 324-330. DOI: 10.1016/j.conbuildmat.2013.11.045

Clemons, C. M. 2002. Interfacing Wood-Plastic Composites Industries in the U.S. Forest Products Journal 52(6): 10-18.

Clemons, C. M., and Iback, R. E. 2004. Effects of Processing Method and Moisture History on Laboratory Fungal Resistance of Wood-HDPE Composites. Forest Product Journal 54(4): 50-57.

Deka, B. K., and Maji, T. K. 2010. Effect of Coupling Agent and Nanoclay on Properties of HDPE, LDPE, PP, PVC Blend and Phargamites karka Nanocomposite. Composites Science and Technology 70(12): 1755-1761. DOI: 10.1016/j.compscitech.2010.07.010

Doan, T. T. L., Gao, S. L., and Mäder, E. 2006. Jute/Polypropylene Composites I. Effect of Matrix Modification. Composites Science and Technology 66(7-8): 952-963. DOI: 10.1016/j.compscitech.2005.08.009

Dobreva, D., Nenkova, S., and Vasileva, S. 2006. Morphology and Mechanical Properties of Polypropylene-Wood Flour Composites. BioResources 1: 209-219.

El-Haggar, S. M., and Kamel, M. A. 2011. Wood Plastic Composites. in: Advances in Composite Materials - Analysis of Natural and Man-Made Materials InTech. DOI: 10.5772/18172

Espert, A., Vilaplana, F., and Karlsson, S. 2004. Comparison of Water Absorption in Natural 
Cellulosic Fibres from Wood and One-Year Crops in Polypropylene Composites and Its Influence on Their Mechanical Properties. Composites Part A: Applied Science and Manufacturing 35(11): 1267-1276. DOI: 10.1016/j.compositesa.2004.04.004

Fabiyi, J. S., McDonald, A. G., Morrell, J. J., and Freitag, C. 2011. Effects of Wood Species on Durability and Chemical Changes of Fungal Decayed Wood Plastic Composites. Composites Part A: Applied Science and Manufacturing 42(5): 501-510. DOI: 10.1016/j.compositesa.2011.01.009

Fabiyi, J. S., McDonald, A. G., Wolcott, M. P., and Griffiths, P. R. 2008. Wood Plastic Composites Weathering: Visual Appearance and Chemical Changes. Polymer Degradation and Stability 93(8): 1405-1414. DOI: 10.1016/j.polymdegradstab.2008.05.024

Fang, Y., Wang, Q., Guo, C., Song, Y., and Cooper, P. A. 2013. Effect of Zinc Borate and Wood Flour on Thermal Degradation and Fire Retardancy of Polyvinyl Chloride (PVC) Composites. Journal of Analytical and Applied Pyrolysis 100: 230-236. DOI: 10.1016/j.jaap.2012.12.028

Farhadinejad, Z., Ehsani, M., Khosravian, B., and Ebrahimi, G. 2012. Study of Thermal Properties of Wood Plastic Composite Reinforced with Cellulose Micro Fibril and Nano Inorganic Fiber Filler. European Journal of Wood and Wood Products 70(6): 823-828. DOI: 10.1007/s00107-012-0630-y

Farsheh, A. T., Talaeipour, M., Hemmasi, A. H., Khademieslam, H., and Ghasemi, I. 2011. Investigation on the Mechanical and Morphological Properties of Foamed Nanocomposites based on Wood Flour/PVC/Multi-Walled Carbon Nanotube. BioResources 6(1): 841-852.

Faruk, O., and Matuana, L. M. 2008. Nanoclay Reinforced HDPE as a Matrix for Wood-Plastic Composites. Composites Science and Technology 68(9): 2073-2077. DOI: 10.1016/j.compscitech.2008.03.004

García, M., Hidalgo, J., Garmendia, I., and García-Jaca, J. 2009. Wood-Plastics Composites with better Fire Retardancy and Durability Performance. Composites Part A: Applied Science and Manufacturing 40(11): 1772-1776. DOI: 10.1016/j.compositesa.2009.08.010

Gardner, D. J., Han, Y., and Wang, L. 2015. Wood-Plastic Composite Technology. Current Forestry Reports 1(3): 139-150. DOI: 10.1007/s40725-015-0016-6

Gardner, D. J., and Murdock, D. 2002. Extrusion of Wood Plastic Composites. Advanced Engineered Wood Composites Center. Brewer, Main, U.S.

Gassan, J., and Bledzki, A. K. 2000. Possibilities to Improve the Properties of Natural Fiber Reinforced Plastics by Fiber Modification - Jute Polypropylene Composites. Applied Composite Materials 7(5-6): 373-385. DOI: 10.1023/A:1026542208108

Gebhardt, A. 2011. Understanding Additive Manufacturing. Hanser Publications, Cincinnati. DOI: $10.3139 / 9783446431621$

George, J., Bhagawan, S. S., Prabhakaran, N., and Thomas, S. 1995. Short Pineapple-Leaf-FiberReinforced Low-Density Polyethylene Composites. Journal of Applied Polymer Science 57(7): 843-854. DOI: 10.1002/app.1995.070570708

Georgopoulos, S. T., Tarantili, P. A., Avgerinos, E., Andreopoulos, A. G., and Koukios, E. G. 2005. Thermoplastic Polymers Reinforced with Fibrous Agricultural Residues. Polymer Degradation and Stability 90(2): 303-312. DOI: 10.1016/j.polymdegradstab.2005.02.020

Ghasemi, I., and Kord, B. 2009. Long-Term Water Absorption Behaviour of Polypropylene/Wood Flour/Organoclay Hybrid Nanocomposite. Iranian Polymer Journal 18(9): 683-691.

Gosselin, R., Rodrigue, D., and Riedl, B. 2006. Injection Molding of Postconsumer Wood-Plastic 
Composites I: Morphology. Journal of Thermoplasctic Composite Materials 19(6): 639-657. DOI: $10.1177 / 0892-705706067484$

Griswold, B. M. 2006. Old Computers to be Recycled into Decking. Plastic News 1-3.

Gwon, J. G., Lee, S. Y., Chun, S. J., Doh, G. H., and Kim, J. H. 2010. Effects of Chemical Treatments of Hybrid Fillers on the Physical and Thermal Properties of Wood Plastic Composites. Composites Part A: Applied Science and Manufacturing 41(10): 1491-1497. DOI: 10.1016/j.compositesa.2010.06.011

Hetzer, M., and De Kee, D. 2008. Wood/Polymer/Nanoclay Composites, Environmentally Friendly Sustainable Technology: A Review. Chemical Engineering Research and Design 86(10): 1083-1093. DOI: 10.1016/j.cherd.2008.05.003

Holbery, J., and Houston, D. 2006. Natural-Fiber-Reinforced Polymer Composites in Automotive Applications. JOM 58(11): 80-86. DOI: 10.1007/s11837-006-0234-2

Homami, S. S., Seydei, M. K., and Moradi, S. 2013. Preparation of Wood Plastic Composite with High Density Polyethylene and Bagasse. World Applied Sciences Journal 21(9): 1302-1304. DOI: 10.5829/idosi.wasj.2013.21.9.2669

Hong, M. K., Lubis, M. A. R., Park, B. D., Sohn, C. H., and Roh, J. 2020. Effects of Surface Laminate Type and Recycled Fiber Content on Properties of Three-Layer Medium Density Fiberboard. Wood Material Science and Engineering 15(3): 163-171. DOI: 10.1080/17480272.2018.1528479

Jayaraman, K. 2003. Manufacturing Sisal-Polypropylene Composites with Minimum Fibre Degradation. Composites Science and Technology 63(3-4): 367-374. DOI: 10.1016/S02663538(02)00217-8

John, M. J., and Thomas, S. 2008. Biofibres and Biocomposites. Carbohydrate Polymers 71(3): 343-364. DOI: 10.1016/j.carbpol.2007.05.040

Johnson, R. K., Zink-Sharp, A., Renneckar, S. H., and Glasser, W. G. 2008. Mechanical Properties of Wetlaid Lyocell and Hybrid Fiber-Reinforced Composites with Polypropylene. Composites Part A: Applied Science and Manufacturing 39(3): 470-477. DOI: 10.1016/j.compositesa.2007.12.007

Jördens, C., Wietzke, S., Scheller, M., and Koch, M. 2010. Investigation of the Water Absorption in Polyamide and Wood Plastic Composite by Terahertz Time-Domain Spectroscopy. Polymer Testing 29(2): 209-215. DOI: 10.1016/j.polymertesting.2009.11.003

Kabir, M.M., Wang, H., Lau, K.T., and Cardona, F. 2012. Chemical Treatments on Plant-Based Natural Fibre Reinforced Polymer Composites: An Overview. Composites Part B: Engineering 43(7): 2883-2892. DOI: 10.1016/j.compositesb.2012.04.053

Kamdem, D. P., Jiang, H., Cui, W., Freed, J., and Matuana, L. M. 2004. Properties of Wood Plastic Composites Made of Recycled HDPE and Wood Flour from CCA-Treated Wood Removed from Service. Composites Part A: Applied Science and Manufacturing 35(3): 347-355. DOI: 10.1016/j.compositesa.2003.09.013

Kamel, S. 2007. Nanotechnology and Its Applications in Lignocellulosic Composites, a Mini Review. Express Polymer Letters 1(9): 546-575. DOI: 10.3144/expresspolymlett.2007.78

Karmaker, A. C., and Youngquist, J. A. 1996. Injection Molding of Polypropylene Reinforced with Short Jute Fibers. Journal of Applied Polymer Science 62: 1147-1151. DOI: 10.1002/(sici)1097-4628(19961121)62:8<1147::aid-app2>3.0.co;2-i

Karmarkar, A., Chauhan, S. S., Modak, J. M., and Chanda, M. 2007. Mechanical Properties of Wood-Fiber Reinforced Polypropylene Composites: Effect of a Novel Compatibilizer with 
Isocyanate Functional Group. Composites Part A: Applied Science and Manufacturing 38(2): 227-233. DOI: 10.1016/j.compositesa.2006.05.005

Keener, T. J., Stuart, R. K., and Brown, T. K. 2004. Maleated Coupling Agents for Natural Fibre Composites. Composites Part A: Applied Science and Manufacturing 35(3): 357-362. DOI: 10.1016/j.compositesa.2003.09.014

Khalid, M., Ali, S., Abdullah, L. C., Ratnam, C. T., and Choong, S. Y. T. 2006. Effect of MAPP as Coupling Agent on the Mechanical Properties of Palm Fiber Empty Fruit Bunch and Cellulose Polypropylene Biocomposites. International Journal of Engineering and Technology 3(1): 79-84.

Kim, J. P., Yoon, T. H., Mun, S. P., Rhee, J. M., and Lee, J. S. 2006. Wood-Polyethylene Composites using Ethylene-Vinyl Alcohol Copolymer as Adhesion Promoter. Bioresource Technology 97(3): 494-499. DOI: 10.1016/j.biortech.2005.02.048

Kord, B. 2011. Effect of Bark Flour Content on Mechanical Properties of Wood Plastic Composites. World Applied Sciences Journal 14(3): 398-401.

Kord, B., and Kiakojouri, S. 2011. Effect of Nanoclay Dispersion on Physical and Mechanical Properties of Wood Flour/Polypropylene/Glass Fibre Hybrid Composites. BioResources 6: 1741-1751.

Kordkheili, H. Y., Farsi, M., and Rezazadeh, Z. 2013. Physical, Mechanical and Morphological Properties of Polymer Composites Manufactured from Carbon Nanotubes and Wood Flour. Composites Part B: Engineering 44(1): 750-755. DOI: 10.1016/j.compositesb.2012.04.023

Kordkheili, H. Y., Hiziroglu, S., and Farsi, M. 2012. Some of the physical and mechanical properties of cement composites manufactured from carbon nanotubes and bagasse fiber. Materials \& Design Elsevier Ltd 33: 395-398. DOI: 10.1016/j.matdes.2011.04.027

Kuo, P. Y., Wang, S. Y., Chen, J. H., Hsueh, H. C., and Tsai, M. J. 2009. Effects of Material Compositions on the Mechanical Properties of Wood-Plastic Composites Manufactured by Injection Molding. Materials and Design 30(9): 3489-3496. DOI: 10.1016/j.matdes.2009.03.012

Lee, S. Y., Kang, I. A., Doh, G. H., Kim, W. J., Kim, J. S., Yoon, H. G., and Wu, Q. 2008. Thermal, Mechanical and Morphological Properties of Polypropylene/Clay/Wood Flour Nano composites. Express Polymer Letters 2(2): 78-87. DOI: 10.3144/expresspolymlett.2008.11

Lei, B., Zhang, Y., He, Y., Xie, Y., Xu, B., Lin, Z., Huang, L., Tan, S., Wang, M., and Cai, X. 2015. Preparation and Characterization of Wood-Plastic Composite Reinforced by Graphitic Carbon Nitride. Materials and Design 66: 103-109. DOI: 10.1016/j.matdes.2014.10.041

Lertwimolnun, W., and Vergnes, B. 2005. Influence of Compatibilizer and Processing Conditions on the Dispersion of Nanoclay in a Polypropylene Matrix. Polymer 46(10): 3462-3471. DOI: 10.1016/j.polymer.2005.02.018

Li, X., Lei, B., Lin, Z., Huang, L., Tan, S., and Cai, X. 2014. The Utilization of Bamboo Charcoal enhances Wood Plastic Composites with Excellent Mechanical and Thermal Properties. Materials and Design 53: 419-424. DOI: 10.1016/j.matdes.2013.07.028

Li, X., Tabil, L. G., and Panigrahi, S. 2007. Chemical Treatments of Natural Fiber for use in Natural Fiber-Reinforced Composites: A Review. Journal of Polymers and the Environment 15(1): 25-33. DOI: $10.1007 / \mathrm{s} 10924-006-0042-3$

Loos, J., Alexeev, A., Grossiord, N., Koning, C. E., and Regev, O. 2005. Visualization of SingleWall Carbon Nanotube (SWNT) Networks in Conductive Polystyrene Nanocomposites by Charge Contrast Imaging. Ultramicroscopy 104(2): 160-167. DOI: 


\subsection{6/j.ultramic.2005.03.007}

Lubis, M. A. R., and Park, B. D. 2020. Enhancing the Performance of Low Molar Ratio UreaFormaldehyde Resin Adhesives via In-Situ Modification with Intercalated Nanoclay. The Journal of Adhesion (Article in Press). DOI: 10.1080/00218464.2020.1753515

Lundin, T., Falk, R. H., and Felton, C. 2001. Accelerated Weathering of Natural FiberThermoplastic Composites: Effects of Ultraviolet Exposure on Bending Strength and Stiffness. The Sixth International Conference on Woodfiber-Plastic Composites. May 1516, 2001. The Madison Concourse Hotel Madison, Wisconsin.

Magaraphan, R., Lilayuthalert, W., and Sirivat, A. 2001. Preparation, Structure, Properties and Thermal Behavior of Rigid-Rod Polyimide/Montmorillonite Nanocomposites. Composites Science and Technology 61: 1253-1264.

Markarian, J. 2008. Outdoor Living Space Drives Growth in Wood-Plastic Composites. Plastics, Additives and Compounding 10(4): 20-25. DOI: 10.1016/s1464-391x(08)70131-4

Metin, D., Tihminlioğlu, F., Balköse, D., and Ülkü, S. 2004. The Effect of Interfacial Interactions on the Mechanical Properties of Polypropylene/Natural Zeolite Composites. Composites Part A: Applied Science and Manufacturing 35(1): 23-32. DOI: 10.1016/j.compositesa.2003.09.021

Migneault, S., Koubaa, A., Erchiqui, F., Chaala, A., Englund, K., and Wolcott, M. P. 2009. Effects of Processing Method and Fiber Size on the Structure and Properties of Wood-Plastic Composites. Composites Part A: Applied Science and Manufacturing 40(1): 80-85. DOI: 10.1016/j.compositesa.2008.10.004

Mwaikambo, L. Y., and Ansell, M. P. 1999. The Effect of Chemical Treatment on the Properties of Hemp, Sisal, Jute and Kapok for Composite Reinforcement. Angewandte Makromolekulare Chemie. DOI: 10.1002/(sici)1522-9505(19991201)272:1<108::aidapmc108>3.3.co;2-0

Ndiaye, D., and Tidjani, A. 2012. Effects of Coupling Agents on Thermal Behavior and Mechanical Properties of Wood Flour/Polypropylene Composites. Journal of Composite Materials 46(2): 3067-3075. DOI: 10.1177/0021998311435675

Njuguna, J., Pielichowski, K., and Desai, S. 2008. Nanofiller-Reinforced Polymer Nanocomposites. Polymer Advance Technology 19(8): 947-959. DOI: 10.1002/pat.1074

Odenberger, P. T., Andersson, H. M., and Lundström, T. S. 2004. Experimental Flow-Front Visualisation in Compression Moulding of SMC. Composites Part A: Applied Science and Manufacturing 35(10): 1125-1134. DOI: 10.1016/j.compositesa.2004.03.019

Okamoto, M. 2006. Recent Advances in Polymer/Layered Silicate Nanocomposites: An Overview from Science to Technology. Materials Science and Technology 22(7): 756-779. DOI: 10.1179/174328406X101319

Panthapulakkal, S., Zereshkian, A., and Sain, M. 2006. Preparation and Characterization of Wheat Straw Fibers for Reinforcing Application in Injection Molded Thermoplastic Composites. Bioresource Technology 97(2): 265-272. DOI: 10.1016/j.biortech.2005.02.043

Park, S. J., Seo, D. I., and Lee, J. R. 2002. Surface Modification of Montmorillonite on Surface Acid-Base Characteristics of Clay and Thermal Stability of Epoxy/Clay Nanocomposites. Journal of Colloid and Interface Science 251(1): 160-165. DOI: 10.1006/jcis.2002.8379

Rahman, K. S., Islam, M. N., Rahman, M. M., Hannan, M. O., Dungani, R., and Khalil, H. A. 2013. Flat-Pressed Wood Plastic Composites from Sawdust and Recycled Polyethylene Terephthalate (PET): Physical and Mechanical Properties. SpringerPlus 2: 629. DOI: 


\subsection{6/2193-1801-2-629}

Ratanawilai, T., Thanawattanasirikul, N., and Homkhiew, C. 2012. Mechanical and Thermal Properties of Oil Palm Wood Sawdust Reinforced Post-Consumer Polyethylene Composites. ScienceAsia 38(3): 289-294. DOI: 10.2306/scienceasia1513-1874.2012.38.289

Ray, D., Sarkar, B. K., and Bose, N. R. 2002. Impact Fatigue Behaviour of Vinylester Resin Matrix Composites Reinforced with Alkali Treated Jute Fibres. Composites Part A: Applied Science and Manufacturing 33(2): 233-241. DOI: 10.1016/s1359-835x(01)00096-3

Ren, W., Zhang, D., Wang, G., and H. C. 2014. Mechanical and Thermal Properties of Bamboo Pulp Fiber Reinforced Polyethylene Composites. BioResources 9(3): 4117-4127.

Tong, J. Y., Royan, N. R. R., Chuen Ng, Y., Ab Ghani, M. H., and Ahmad, S. 2014. Study of the Mechanical and Morphology Properties of Recycled HDPE Composite using Rice Husk Filler. Advances in Materials Science and Engineering 2014: 938961. DOI: $10.1155 / 2014 / 938961$

Rude, E. F. 2007. Evaluation of Coupling Mechanisms in Wood Plastic Composites. Thesis. Washington State University, U.S.

Sain, M., Park, S. H., Suhara, F., and Law, S. 2004. Flame Retardant and Mechanical Properties of Natural Fibre-PP Composites Containing Magnesium Hydroxide. Polymer Degradation and Stability 83(2): 363-367. DOI: 10.1016/S0141-3910(03)00280-5

Salmah, H., Ruzaidi, C. M., and Ghani, S. A. 2007. The Effect of Coupling Agent on Thermal Properties and Morphology of Paper Sludge Filled Polypropylene (PP)/Ethylene Propylene Diene Terpolymer (EPDM) Composites. Working Paper. Universiti Malaysia Perlis (UniMAP), Malaysia.

Schadler, L. S., Brinson, L. C., and Sawyer, W. G. 2007. Polymer Nanocomposites: A Small Part of the Story. JOM 59(3): 53-60. DOI: 10.1007/s11837-007-0040-5

Segerholm, K. 2007. Wood Plastic Composites made from Modified Wood: Aspects on Moisture Sorption, Micromorphology and Durability. Working Paper. School of Architecture and the Built Environment, Royal Institute of Technlogy.

Sheshmani, S., Ashori, A., and Fashapoyeh, M. A. 2013. Wood Plastic Composite using Graphene Nanoplatelets. International Journal of Biological Macromolecules 58: 1-6. DOI: 10.1016/j.ijbiomac.2013.03.047

Sihombing, H., Rassiah, K., Ashaari, Z., and Yuharzi, M. Y. 2012. Analysis and Development of Recycled Materials for Wood Plastic Composite Product. Elixir Mechanical Engineering 51: 10834-10840.

Singh-Beemat, J., and Iroh, J. O. 2012. Characterization of Corrosion Resistant Clay/Epoxy Ester Composite Coatings and Thin Films. Progress in Organic Coatings 74(1): 173-180. DOI: 10.1016/j.porgcoat.2011.12.006

Srikanth, M., Misak, H., and Asmatulu, R. 2013. Evaluating Nanosafety of Nanomaterials by Invitro Cytotoxicity Tests on Fibroblast Cells. In Proceedings: 9th Annual Symposium: Graduate Research and Scholarly Projects. Wichita, KS: Wichita State University, p.85-86.

Stark, N. M., Matuana, L. M., and Clemons, C. M. 2004. Effect of Processing Method on Surface and Weathering Characteristics of Wood-Flour/HDPE Composites. Journal of Applied Polymer Science 93(3): 1021-1030. DOI: 10.1002/app.20529

Stark, N. M., and Rowlands, R. E. 2003. Effects of Wood Fiber Characteristics on Mechanical Properties of Wood/Polypropylene Composites. Wood and Fiber Science 35(2): 167-174. DOI: $10.1016 / \mathrm{s} 0008-8846(03) 00193-5$ 
Stark, N. M., White, R. H., Mueller, S. A., and Osswald, T. A. 2010. Evaluation of Various Fire Retardants for Use in Wood Flour-Polyethylene Composites. Polymer Degradation and Stability 95(9): 1903-1910. DOI: 10.1016/j.polymdegradstab.2010.04.014

Sykacek, E., Hrabalova, M., Frech, H., and Mundigler, N. 2009. Extrusion of Five Biopolymers Reinforced with Increasing Wood Flour Concentration on a Production Machine, Injection Moulding and Mechanical Performance. Composites Part A: Applied Science and Manufacturing 40(8): 1272-1282. DOI: 10.1016/j.compositesa.2009.05.023

Taib, R. M., Zauzi, N. S. A., Ishak, Z. a M., and Rozman, H. D. 2010. Effects of Photo-Stabilizers on the Properties of Recycled High-Density Polyethylene (HDPE)/Wood Flour (WF) Composites Exposed to Natural Weathering. PRIM Malaysia Polymer Journal 5(2): 193 203.

Tajan, M., Chaiwutthinan, P., and Leejarkpai, T. 2008. Thermal and Mechanical Properties of Wood-Plastic Composites from Iron Wood Flour and Recycled Polypropylene Foam. Journal of Metals, Materials and Minerals 18(2): 53-56.

Wang, Y. 2007. Morphological Characterization of Wood Plastic Composite (WPC) with Advanced Imaging Tools: Developing Methodologies for Reliable Phase and Internal Damage Characterization. Thesis. Oregon State University, U.S.

WRAP. 2003. Wood Plastic Composite Study-Technology and UK Market Opportunities. The Waste and Reources Action Programme (WRAP). Banbury, UK.

Wolcott, M. P. 1999. A Technology Review of WPC. 33rd International Particleboard/Composite Materials Symposium.

Xie, Y., Hill, C. a S., Xiao, Z., Militz, H., and Mai, C. 2010. Silane Coupling Agents used for Natural Fiber/Polymer Composites: A Review. Composites Part A: Applied Science and Manufacturing 41(7): 806-819. DOI: 10.1016/j.compositesa.2010.03.005

Yadav, S. M., Lubis, M. A. R., Wibowo, E. S., and Park, B. 2020. Effects of Nanoclay Modification with Transition Metal Ion on the Performance of Urea-Formaldehyde Resin Adhesives. Polymer Bulletin. DOI: 10.1007/s00289-020-03214-3

Yang, B. Z., Seale, R. D., Dahlen, J., Shmulsky, R., and Jones, P. D. 2014. Bending Properties of a Novel Engineered Composite from Southern Pine Lumber. European Journal of Wood and Wood Products 72(5): 601-607. DOI: 10.1007/s00107-014-0821-9

Yeh, S. K. 2007. Polypropylene-Based Wood-Plastic Composites Reinforced with Nanoclay. Dissertation. West Virginia University. West Virginia, U.S.

Yeh, S. K., Agarwal, S., and Gupta, R. K. 2009. Wood-Plastic Composites Formulated with Virgin and Recycled ABS. Composites Science and Technology 69(13): 2225-2230. DOI: 10.1016/j.compscitech.2009.06.007

Yeh, S. K., and Gupta, R. K. 2008. Improved Wood-Plastic Composites through better Processing. Composites Part A: Applied Science and Manufacturing 39(11): 1694-1699. DOI: 10.1016/j.compositesa.2008.07.013

Yue, L., Pircheraghi, G., Monemian, S. A., and Manas-Zloczower, I. 2014. Epoxy Composites with Carbon Nanotubes and Graphene Nanoplatelets - Dispersion and synergy effects. Carbon 78: 268-278. DOI: 10.1016/j.carbon.2014.07.003

Zhou, X., Yu, Y., Lin, Q., and Chen, L. 2013. Effects of Maleic Anhydride-Grafted Polypropylene (MAPP) on the Physico-Mechanical Properties and Rheological Behavior of Bamboo Powder-Polypropylene Foamed Composites. BioResources 8(4): 6263-6279.

Zolfaghari, A., Behravesh, A. H., and Adli, A. 2013. Continuous Glass Fiber Reinforced Wood 
Plastic Composite in extrusion Process: Mechanical Properties. Materials and Design 51: 701-708. DOI: 10.1016/j.matdes.2013.04.082 